\title{
Photoredox Chemistry of Chloromercurate(II) Complexes in Acetonitrile
}

\author{
Ottó Horváth",1 and Arnd Vogler* \\ Institut für Anorganische Chemie, Universität Regensburg, Universitätsstrasse 31, \\ 93053 Regensburg, Germany
}

Received May 19, $1993^{\circ}$

The kinetically labile chloromercurates(II) have rather high stepwise formation constants in acetonitrile; even for $\mathrm{HgCl}_{4}{ }^{2-}$ a value of $1.07 \times 10^{4} \mathrm{M}^{-1}$ was determined. The ultraviolet spectra of these complexes are characterized by ligand-to-metal charge-transfer transitions of different energies and intensities. Their photolysis leads to the formation of $\mathrm{Hg}(\mathrm{I})$ and $\mathrm{Cl}$ in the primary photochemical reaction. The mercury(I) monomers recombine to give $\mathrm{Hg}_{2} \mathrm{Cl}_{2}$, while chlorine radicals are reconverted to $\mathrm{Cl}^{-}$, increasing the $\mathrm{Cl}-/ \mathrm{Hg}$ (II) ratio in the solution. In considerable excess of $\mathrm{Cl}^{-}\left(\left[\mathrm{Cl}^{-}\right]=5 \times 10^{-3} \mathrm{M}\right.$ at $\left.4.5 \times 10^{-5} \mathrm{M} \mathrm{HgCl}_{4}{ }^{2-}\right)$ mercury(I) species undergo disproportionation giving $\mathrm{Hg}^{\mathrm{O}}$ as end product. The higher the ligand number of the complex, the lower is the quantum yield for the overall reaction: $5.310^{-2}, 1.35 \times 10^{-2}$, and $9.5 \times 10^{-3}$ for $\mathrm{HgCl}_{2}, \mathrm{HgCl}_{3}^{-}$, and $\mathrm{HgCl}_{4}{ }^{2-}$, respectively, in deaerated solution at $\lambda_{\mathrm{ir}}=254 \mathrm{~nm}$. In the presence of air quantum yields are lower and the main product is $\mathrm{Hg}_{2} \mathrm{Cl}_{2}$ in all cases. Ethanol enhances the efficiency of the photoreduction but only in argon-saturated systems, indicating competitive reactions of the $\mathrm{Hg}(\mathrm{I})$ monomers formed in the primary step and a considerable oxygen sensitivity of $\mathrm{Hg}^{0}$ as well.

\section{Introduction}

As well-known, mercury displays chemical similarities to both transition and main-group metals. Thus, $\mathrm{Hg}^{2+}$ having filled $\mathrm{d}$ and empty $s$ and $p$ subshells readily forms kinetically labile complexes with halo and pseudohalo ligands in various solvents as do numerous other metal ions of $(n-1) d^{10} n s^{0}$ configuration..$^{2,3}$ If the metal center of such a complex is in a higher oxidation state, its electronic absorption spectrum is featured by LMCT transitions. The energies and intensities of the corresponding bands strongly depend on the coordination number as in the case of the halomercurate(II) complexes, $\mathrm{HgX}_{n}{ }^{(n-2)-}(\mathrm{X}=\mathrm{Cl}, \mathrm{Br}, \mathrm{I}$; $n=2-4){ }^{4}$ Hence, their photoactivities can also be significantly influenced by $n$.

Although the light sensitivity of inorganic mercury(II) complexes has been known for many decades, ${ }^{5}$ a more intense photochemical investigation of these compounds started only in the past few years. 6 Irrespectively of the ligands, the primary photoreaction of the $\mathrm{Hg}$ (II) complexes studied so far (e.g. $\left.\mathrm{Hg}\left(\mathrm{N}_{3}\right)_{3}-\mathrm{Hg}(\mathrm{CN})_{2}\right)$ was the reduction of the metal center, due to LMCT excitations. ${ }^{7,8}$ Also in the photoinduced metal to metal charge-transfer reactions in $\left[(\mathrm{NC})_{2} \mathrm{Hg}^{\mathrm{IINCFe}}(\mathrm{CN})_{5}\right]^{4-}$ and $\left[\mathrm{Hg}^{\mathrm{II}} \mathrm{CO}_{2}{ }^{\mathrm{I}}(\mathrm{CN})_{10}\right]^{6-}$ complexes, mercury(II) played the role of the electron acceptor. ${ }^{9}$ A flash photolysis study by Langmuir and Hayon proved the formation of the $\mathrm{X}_{2}$ - radical ion in aqueous solutions of halomercurates(II), ${ }^{10}$ but no quantum yield deter-

- Abstract published in Advance ACS Abstracts, October 15, 1993.

(1) On research leave as Alexander von Humboldt Fellow from the Department of General and Inorganic Chemistry, University of Veszprem, H-8201 Veszprém, P.O.B. 158, Hungary.

(2) (a) Martell, A. E.; Sillen, L. G. Stability Constants of Metal-Ion Complexes. Special Publ. No. 17; The Chemical Society: London, 1964. (b) Martell, A. E.; Sillen, L. G. Stability Constants of Metal-Ion Complexes. Special Publ. No. 25; The Chemical Society: London, 1971. (c) Hogfeldt, E. Stability Constants of Metal-Ion Complexes, Part A Inorganic Ligands; Pergamon Press: Oxford, U.K., 1982.

(3) Cotton, F. A.; Wilkinson, G. Advanced Inorganic Chemistry; Wiley-Interscience: New York, 1988.

(4) Griffiths, T. R.; Anderson, R. A. Can. J. Chem. 1991, 69, 451.

(5) Balzani, V.; Carassiti, V. Photochemistry of Coordination Compounds; Academic Press: New York, 1970; pp 277-81.

(6) Horváth, O.; Stevenson, K. L. Charge Transfer Photochemistry of Coordination Compounds; VCH: New York, 1993; pp 76-79.

(7) Kunkely, H.; Vogler, A. Polyhedron 1989, 8, 2731.

(8) Rehorek, D.; Janzen, E. G. Z. Chem. 1985, 25, 69

(9) Kunkely, H.; Stochel, G.; Vogler, A. Z. Naturforsch., B: Chem. Sci. $1989,44,145$

(10) Langmuir, M. E.; Hayon, E. J. Phys. Chem. 1967, 71, 3808. mination was done. Besides, aprotic solvents which are rather weakly coordinated to $\mathrm{Hg}^{2+}$ can be more favorable to investigate the role of the complex equilibria in the photochemistry of these compounds. In this work we studied the photoredox behavior of chloromercurate(II) complexes in acetonitrile in order to elucidate how the number of the coordinated ligands affects the photoactivity and what kind of reaction mechanism is operative in this system.

\section{Experimental Section}

All solutions were prepared to the desired concentration from stock solutions of reagent grade and suitably dried $\mathrm{HgCl}_{2}, \mathrm{LiCl}$, and $\mathrm{Et} 4 \mathrm{NCl}$. Dry spectrograde $\mathrm{CH}_{3} \mathrm{CN}$ was used as solvent. Ethanol of the same quality was applied as a reductive agent for mechanistic experiments.

Absorption spectra were taken on an Uvikon 860 double-beam spectrophotometer, using $1-\mathrm{cm}$ and $1-\mathrm{mm}$ quartz cuvettes. Typically the photolyses were carried out with $2.5-\mathrm{mL}$ solutions in $1-\mathrm{cm}$ cells at room temperature. Oxygen-free samples were prepared by purging with $\mathrm{CH}_{3-}$ $\mathrm{CN}$-saturated argon for at least $1 \mathrm{~h}$ before the irradiation. A Hanovia $\mathrm{Xe} / \mathrm{Hg} 977$ B-1 (1000 W) lamp equipped with a Schoeffel GM 250-1 monochromator served as the light source. Incident light intensity $\left(I_{0}\right.$ $=7.0 \times 10^{-6} \mathrm{~mol}$ photon $\mathrm{dm}^{-3} \mathrm{~s}^{-1}$ at $254 \mathrm{~nm}$ ) was determined by a Polytec pyroelectric radiometer calibrated and equipped with an RkP-345 detector. Experiments for quantum yield determination were carried out with samples of nearly $100 \%$ light absorption.

Time-resolved absorption measurements were obtained in Veszprem University's laser photolysis system described elsewhere. ${ }^{11}$ Pulse energies of $10-20 \mathrm{~mJ}$ at $266 \mathrm{~nm}$ with a width of about $15 \mathrm{~ns}$ were used in these experiments.

\section{Results}

Spectroscopy and Equilibria. The UV absorption spectrum of $\mathrm{HgCl}_{2}$ in acetonitrile is rather featureless; it displays a very broad and moderately large band with a maximum close to $200 \mathrm{~nm}$ (Figure 1, curve a). Gradual addition of chloride (in $4 \times 10^{-5}$ $M$ increments) to the solution of $4.5 \times 10^{-4} \mathrm{M} \mathrm{HgCl}_{2}$ gives rise to the formation of a new band at $240 \mathrm{~nm}$. The increase of its absorbance is proportional to the amount of chloride added until it reaches about $50 \%$ of the $\mathrm{HgCl}_{2}$ concentration (Figure 1). Since the stepwise formation constant of $\mathrm{HgCl}_{3}{ }^{-}, K_{3}$, in acetonitrile is $c a .10^{6} \mathrm{M}^{-1}$, the added chloride ions are quantitatively coordinated to the $\mathrm{Hg}^{2+}$ center. Thus, the molar absorptivity of

(11) Stevenson, K. L.; Berger, R. M.; Grush, M. M.;Stayanoff, J. C.; Horváth A.; Horváth, O.J. Photochem. Photobiol., A 1991, 60, 215. 


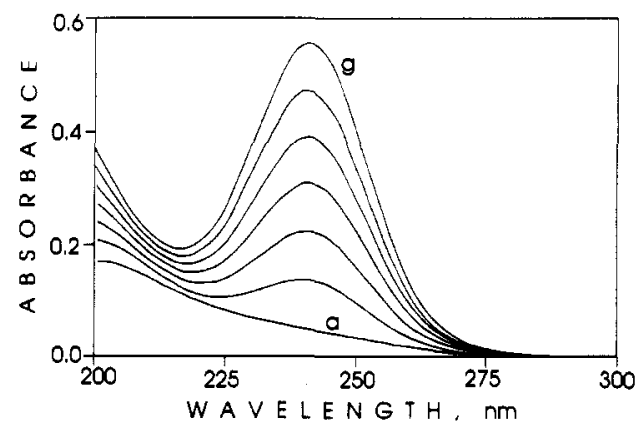

Figure 1. Ultraviolet absorption spectra changes $(a \rightarrow g)$ obtained upon addition of chloride (in $4 \times 10^{-5} \mathrm{M}$ increments) to $\mathrm{HgCl}_{2}\left(4.5 \times 10^{-4}\right.$ $\mathrm{M}$ ) in acetonitrile at room temperature. $l=0.1 \mathrm{~cm}$.

Table I. Molar Absorptivities of Chloromercurate(II) Complexes in Acetonitrile

\begin{tabular}{cccc}
\hline & \multicolumn{3}{c}{$\epsilon_{\mathrm{i}}, \mathrm{M}^{-1} \mathrm{~cm}^{-1}$} \\
\cline { 2 - 4 }$\lambda, \mathrm{nm}$ & $\mathrm{HgCl}_{2}$ & $\mathrm{HgCl}_{3}^{-}$ & $\mathrm{HgCl}_{4}{ }^{-2}$ \\
\hline 234 & 690 & 18100 & 41800 \\
240 & 510 & 21200 & 35800 \\
254 & 145 & 10800 & 5640
\end{tabular}

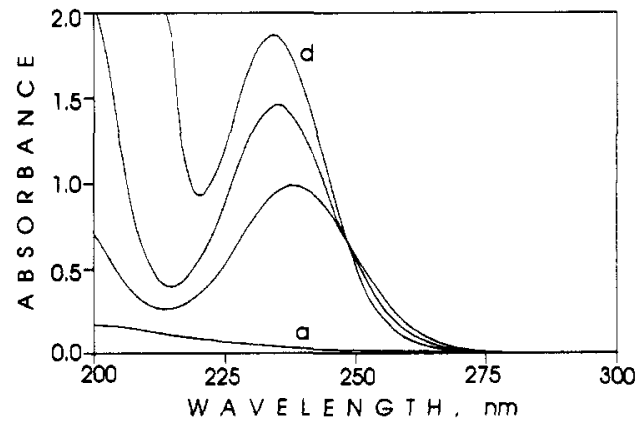

Figure 2. Ultraviolet spectra changes obtained upon addition of (a) 0 (b) $8 \times 10^{-4}$, (c) $2.8 \times 10^{-3}$, and (d) $9.4 \times 10^{-3} \mathrm{M}$ chloride to $\mathrm{HgCl}_{2}$ (4.5 $\times 10^{-4} \mathrm{M}$ ) in acetonitrile at room temperature. $l=0.1 \mathrm{~cm}$

$\mathrm{HgCl}_{3}$ - can be directly determined in this way. The slope of the $A_{240}$ vs $C_{\mathrm{Cl}}$ (added) plot (not shown) is $\epsilon_{3}{ }^{240}-\epsilon_{2}{ }^{240}$, where $\epsilon_{3}{ }^{240}$ and $\epsilon_{2}{ }^{240}$ are the absorption coefficients of $\mathrm{HgCl}_{3}{ }^{-}$and $\mathrm{HgCl}_{2}$, respectively, at $240 \mathrm{~nm}$. Table I summarizes the molar absorbances determined at different wavelengths for $\mathrm{HgCl}_{n}{ }^{(\mathrm{n}-2)-}(n=$ 2-4) complexes in $\mathrm{CH}_{3} \mathrm{CN}$.

Addition of more chloride to this system $\left(\mathrm{C}_{\mathrm{Cl}}\right.$ (added) $>C_{\mathrm{HgCl}_{2}}$ ) results in a slight blue shift of the absorption band, while its intensity increases monotonically further (Figure 2). However, at longer wavelengths a continuous decrease can be observed, giving rise to an isosbestic point at $248 \mathrm{~nm}$. This clearly indicates that basically two species exist in the system at this stage, $\mathrm{HgCl}_{3}-$ and $\mathrm{HgCl}_{4}{ }^{2-}$. About $5.9 \times 10^{-3} \mathrm{M}$ chloride added to $4.5 \times 10^{-4}$ $\mathrm{HgCl}_{2}$ (i.e. $\left[\mathrm{Cl}^{-}\right]=5 \times 10^{-4} \mathrm{M}$ ) is necessary for the $100 \%$ conversion to the tetrachloro complex. This is in accordance with the previous experiences by Day and Seal. ${ }^{12} \mathrm{HgCl}_{4}{ }^{2-}$ shows an absorption band at $234 \mathrm{~nm}$ with the extinction coefficient of $4.18 \times 10^{4} \mathrm{M}^{-1} \mathrm{~cm}^{-1}$. This is also in good agreement with the data published earlier. ${ }^{12}$ Knowing the molar absorbances of both $\mathrm{HgCl}_{3}{ }^{-}$and $\mathrm{HgCl}_{4}{ }^{2-}$ at 234 and $240 \mathrm{~nm}$, the stepwise formation constant of the latter species can be determined using the absorptions measured at different $\left[\mathrm{Cl}^{-}\right]$values. The concentration ratio of the two chloro complexes in equilibrium $\left(R=\left[\mathrm{HgCl}_{4}{ }^{2-}\right] /\right.$ $\left.\left[\mathrm{HgCl}_{3}-\right]\right)$ can be calculated with a simple linear equation: $R \epsilon_{4}$ $+(1-R) \epsilon_{3}=A / C_{\mathrm{HgCl}_{2}}$. Then the $R$ values obtained are plotted as a function of free-ligand concentration $\left(\left[\mathrm{Cl}^{-}\right]=C_{\mathrm{Cl}}\right.$ (added) $\left.-\left[\mathrm{HgCl}_{3}{ }^{-}\right]-2\left[\mathrm{HgCl}_{4}{ }^{2-}\right]\right)$. The equation on the formation

(12) Day, P.; Seal, R. H. J. Chem. Soc., Dalton Trans. 1972, 2054.

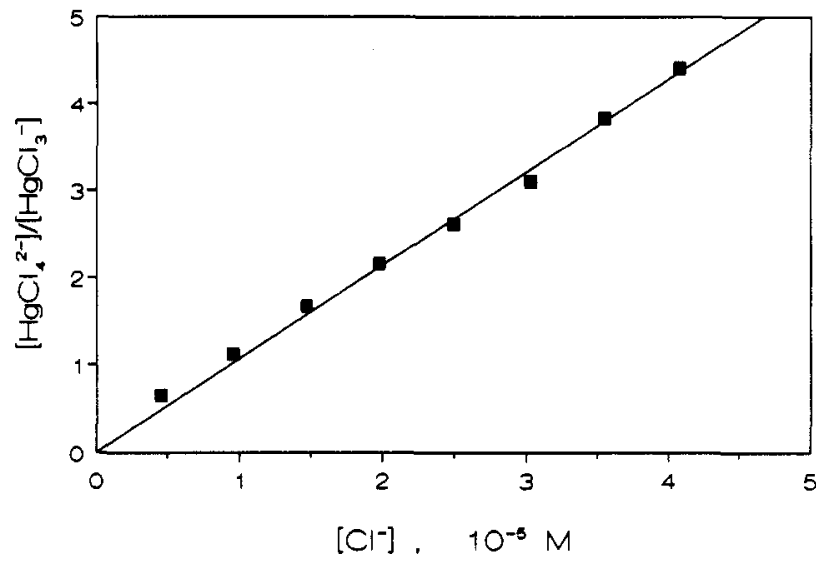

Figure 3. Concentration ratio of tetra- and trichloromercurate(II) vs free-ligand concentration in acetonitrile at room temperature $\left(C_{\mathrm{Hg}(\mathrm{II})}=\right.$ $\left.4.5 \times 10^{-4} \mathrm{M}\right)$

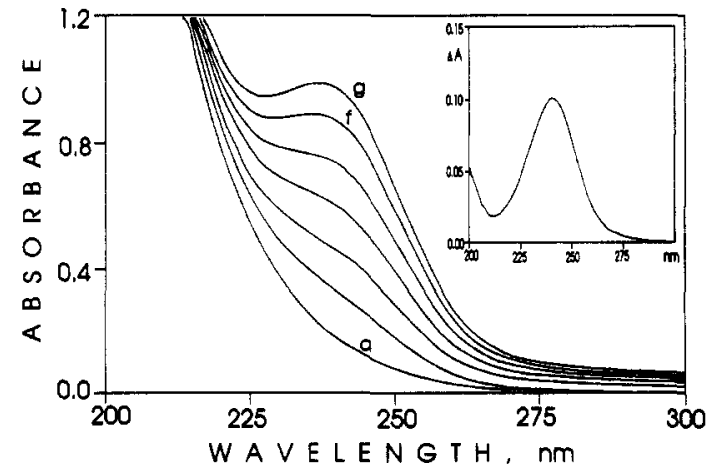

Figure 4. Temporal spectral changes during the photolysis of $5 \times 10^{-3}$ $M \mathrm{HgCl}_{2}$ in argon-saturated $\mathrm{CH}_{3} \mathrm{CN}$ at (a) $0-$, (b) 5-, (c) $10-$, (d) 15 (e) $20-$, (f) $25-$, and $(\mathrm{g}) 30-\mathrm{min}$ irradiation times $\left(\lambda_{\mathrm{ir}}=254 \mathrm{~nm}\right), l=0.1$ $\mathrm{cm}$. Inset: difference spectrum $(\mathrm{g}-\mathrm{f})$.

constant

$$
K_{4}=\left[\mathrm{HgCl}_{4}{ }^{2-}\right] /\left(\left[\mathrm{HgCl}_{3}^{-}\right]\left[\mathrm{Cl}^{-}\right]\right)
$$

predicts a linear relationship with an intercept at the origin. Our results fulfill this expectation (Figure 3), and the slope of the plot gives the value of $(1.07 \pm 0.10) \times 10^{4} \mathrm{M}^{-1}$ for $K_{4}$. This is in accordance with the data measured by Coetzee et al. with polarography $\left(1.58 \times 10^{4} \mathrm{M}^{-1}\right) .^{13}$ However, an earlier result by Ellendt et al. $\left(170 \mathrm{M}^{-1}\right)^{14}$ is more than 1 order of magnitude lower, indicating that conductometry, which they applied, was not a reliable method for this system. Experiments for spectral studies were carried out with both $\mathrm{LiCl}$ and $\mathrm{Et}_{4} \mathrm{NCl}$. No cation size effect was observed, probably due to the relatively low concentrations $\left(C_{\mathrm{Cl}}\right.$ (added) $\left.<10^{-2} \mathrm{M}\right)$. Thus, in the photochemical experiments $\mathrm{LiCl}$ was exclusively applied as a source of added chloride.

Continuous Photolysis. Upon irradiation $\left(\lambda_{\text {ir }}=254 \mathrm{~nm}\right)$ of $\mathrm{HgCl}_{2}$ in argon-saturated $\mathrm{CH}_{3} \mathrm{CN}\left(5 \times 10^{-3} \mathrm{M}\right)$ a monotonic increase of absorption can be observed in the 220-270-nm range (Figure 4). This, on the basis of the difference spectrum (see inset in Figure 4), can be attributed to the formation of $\mathrm{HgCl}_{3}$. Besides, a gradual increase in the baseline absorbance indicates the production of some colloid, namely the practically insoluble $\mathrm{Hg}_{2} \mathrm{Cl}_{2}$.

The formation of trichloromercurate(II) is the consequence of the change in the $\mathrm{Cl}^{-} / \mathrm{Hg}$ (II) ratio in solution, which increases in this case, due to the $\mathrm{Hg}_{2} \mathrm{Cl}_{2}$ production. This explanation assumes that chloride ions do not take part in any other net

(13) Coetzee, J. F.; Campion, J. J.; Liberman, D. R. Anal. Chem. 1973, 45 , 343.

(14) Ellendt, G.; Cruse, K. Z. Physik. Chem. 1952, 201, 130. 
reactions changing their concentration. The primary photoreaction, on the basis of earlier observations in aqueous systems ${ }^{10}$ and evidence presented here later, is a LMCT process generating $\mathrm{Hg}(\mathrm{I})$ and $\mathrm{Cl}$. While mercury(I) forms $\mathrm{Hg}_{2} \mathrm{Cl}_{2}$, chlorine radical is reconverted to $\mathrm{Cl}^{-}$in a thermal redox reaction with the solvent. A similar phenomenon was observed in the photoreduction of chlorocuprate(II) complexes in acetonitrile. ${ }^{15,16}$ Hence, the quantum yield for the overall photoreaction can be determined from the absorbance change $\left(\Delta A_{240}\right)$ due to the $\mathrm{HgCl}_{3}$ formation. Division of $\Delta A_{240}$ by $\Delta \epsilon=\epsilon_{3}{ }^{240}-2 \epsilon_{2} 240$ gives the actual concentration of the trichloromercurate(II) photoproduced because formation of one trichloromercurate(II) complex is accompanied by consumption of two $\mathrm{HgCl}_{2}$ species (converted to $1 /{ }_{2} \mathrm{Hg}_{2} \mathrm{Cl}_{2}$ and $\mathrm{HgCl}_{3}-$ ). In order to determine the quantum yield for photoreaction of $\mathrm{HgCl}_{2}$ the initial slope of the $\left[\mathrm{HgCl}_{3}{ }^{-}\right]$ vs time plot must be taken because of the big difference (about 2 orders of magnitude) between the molar absorbances of $\mathrm{HgCl}_{2}$ and $\mathrm{HgCl}_{3}-$. Otherwise the inner filter effect by the trichloro species would diminish the estimated quantum yield. On the other hand, in this case the absorbance of $\mathrm{Hg}_{2} \mathrm{Cl}_{2}$ should also be taken into consideration, because at the very beginning of the reaction it is comparable with that of $\mathrm{HgCl}_{3}-\left(2.3 \times 10^{4} \mathrm{M}^{-1} \mathrm{~cm}^{-1}\right.$ at $235 \mathrm{~nm}^{17}$ ). At a later stage of the reaction, it contributes much less to the absorption increase, in a form of colloid, due to its very poor solubility.

The quantum yield for the photoreaction of trichloromercurate(II), $\Phi_{3}$, can also be directly measured if photolysis of a solution containing $40 \% \mathrm{HgCl}_{3}-$ and $60 \% \mathrm{HgCl}_{2}$ is carried out. In this case $99 \%$ of the light is absorbed by the trichloro species. Thus, at low conversion a linear $\Delta A_{240}$ vs time plot is obtained, the slope of which corresponds to $\Phi_{3}$.

At an appropriate excess of $\mathrm{Cl}^{-}\left(\geq 5 \times 10^{-3} \mathrm{M}\right)$, mercury(II) exists in this system exclusively as $\mathrm{HgCl}_{4}{ }^{2-}$. Irradiation of such an argon-saturated solution results in a decrease in the absorbance at $234 \mathrm{~nm}$, due to the reduction of tetrachloromercurate(II) (Figure 5a). In this case no change occurs in the complex equilibrium; therefore the absorbance, $A_{234}$, corrected by the slight increase of the baseline, gives the actual concentration of $\mathrm{HgCl}_{4}{ }^{2-}$. The difference spectrum (Figure 5a, inset) clearly shows the formation of atomic mercury, ${ }^{18,19 a, 20}$ while in the presence of air $\mathrm{Hg}_{2} \mathrm{Cl}_{2}$ is the main product giving rise to an isosbestic point at $222 \mathrm{~nm}$ (Figure 5b). As shown, the quantum yields for the photoreactions of each chloromercurate(II) complex in this system can be separately estimated. Table II summarizes the values obtained for both deaerated and air-saturated conditions.

The relatively low quantum yields suggest that an effective back-reaction may be operative between the primary photoproducts, i.e. $\mathrm{HgCl}_{n-1}{ }^{(n-2)-}$ and $\mathrm{Cl}$. Application of some reductive agent which can react with one or both of these species may efficiently hinder the recombination and thus enhance the overall quantum yield. Addition of ethanol (in the concentration range $0-0.15 \mathrm{M}$ ) dramatically increased $\Phi$ for the photoreduction of $\mathrm{HgCl}_{4}{ }^{2-}$ in argon-saturated solutions. The formation of atomic mercury became more pronounced in this case, due to the higher oversaturation as a consequence of the faster reaction. The quantum yield as a function of $C_{\mathrm{EtOH}}$ added shows a monotonic increase in the $0-0.15 \mathrm{M}$ region, reaching a more than 5-fold enhancement compared to the initial value (Figure 6). In the presence of air, however, alcohol shows no effect on the

(15) Cervone, E.; Camassei, F. D.; Giannini, I.; Sykora, J. J. Photochem. 1979, 11,321

(16) Horváth, O.; Papp, S. J. Chem. Educ. 1988, 65, 1102.

(17) Nazhat, N. B.; Asmus, K.-D. J. Phys. Chem. 1973, 77, 614.

(18) (a) Vinogradov, S. N.; Gunning, H. E. J. Phys. Chem. 1962, 68, 68. (b) Mason, W. R. Inorg. Chem. 1988, 27, 437. (c) Phibbs, M. K.; Darwent, B. d. B. J. Chem. Phys. 1950, 18,679.

(19) (a) Calvert, J. G.; Pitts, J. N. Photochemistry; John Wiley: New York, 1966; p 62. (b) Ibid, pp 173-4.

(20) Horváth, O.; Ford, P. C.; Vogler, A. Inorg. Chem. 1993, 32, 2614.
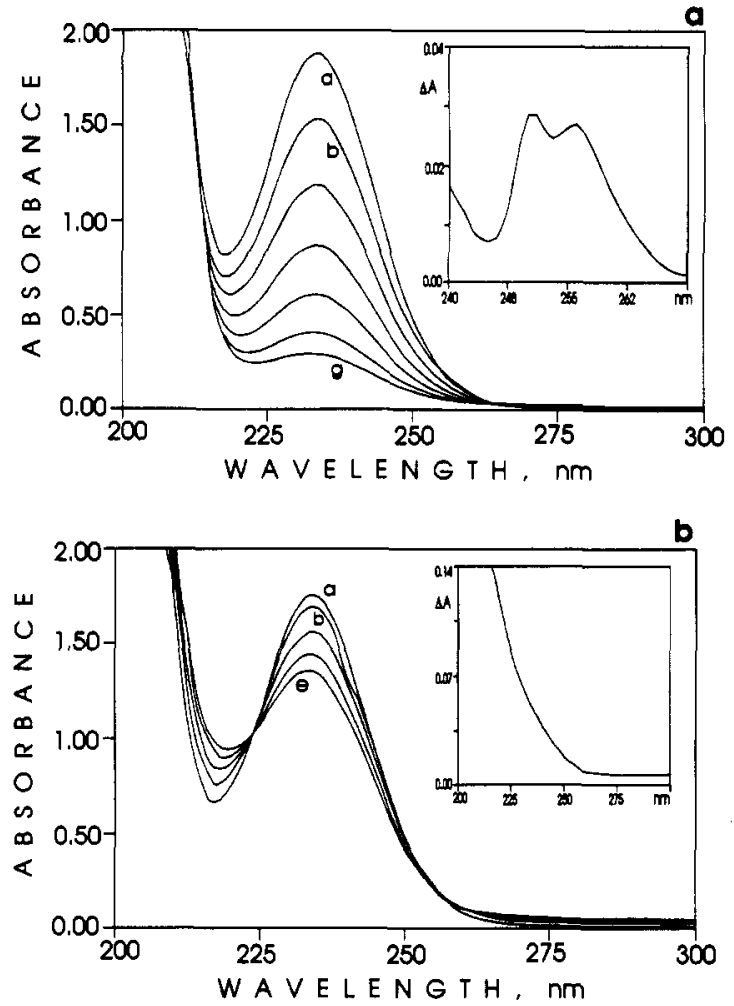

Figure 5. (a) Temporal spectral changes during the photolysis of $4.5 \times$ $10^{-5} \mathrm{M} \mathrm{HgCl}_{4}{ }^{2-}\left(\left[\mathrm{Cl}^{-}\right]=5 \times 10^{-3} \mathrm{M}\right)$ in argon-saturated $\mathrm{CH}_{3} \mathrm{CN}$ at (a) $0-$, (b) 2-, (c) 4-, (d) 6-, (e) 8-, (f) 10-, and (g) 12-min irradiation times $\left(\lambda_{\mathrm{ir}}=254 \mathrm{~nm}\right) . l=1 \mathrm{~cm}$. Inset: difference spectrum $(\mathrm{b}-0.8 \mathrm{a})$. (b) Temporal spectral changes during the photolysis of $4.2 \times 10^{-5} \mathrm{M} \mathrm{HgCl}_{4}{ }^{2-}$ $\left(\left[\mathrm{Cl}^{-}\right]=5 \times 10^{-3} \mathrm{M}\right)$ in aerated $\mathrm{CH}_{3} \mathrm{CN}$ at (a) $0-$, (b) 5-, (c) $10-$, (d) 15-, and (e) 20-min irradiation times $\left(\lambda_{\mathrm{ir}}=254 \mathrm{~nm}\right) . l=1 \mathrm{~cm}$. Inset: difference spectrum $(b-0.94 a)$.

Table II. Individual Quantum Yields for Photoreduction of Chloromercurate(II) Complexes in Acetonitrile $\left(\lambda_{\text {ir }}=254 \mathrm{~nm}\right)$

\begin{tabular}{cccc}
\hline & \multicolumn{3}{c}{$10^{2} \Phi_{\mathrm{i}}{ }^{a}$} \\
\cline { 2 - 4 } condition & $\mathrm{HgCl}_{2}$ & $\mathrm{HgCl}_{3}{ }^{-}$ & $\mathrm{HgCl}_{4}{ }^{2-}$ \\
\hline $\mathrm{Ar}$ & 5.3 & 1.35 & 0.95 \\
air & 3.1 & 0.56 & 0.21
\end{tabular}

- Uncertainty: $\pm 20 \%$ for $\Phi_{2}, \pm 10 \%$ for $\Phi_{3}$ and $\Phi_{4}$.

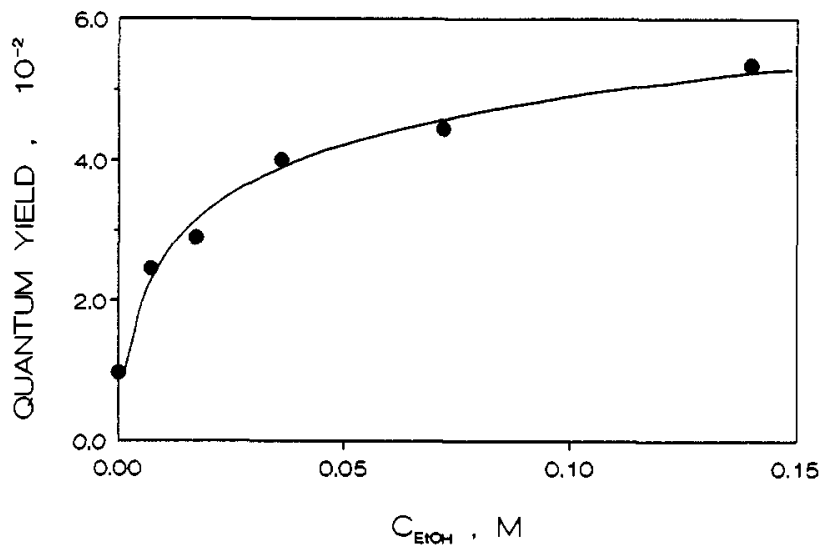

Figure 6. Quantum yield $v$ EtOH concentration plot for the photoreduction of $\mathrm{HgCl}_{4}^{2-}$ in argon-saturated $\mathrm{CH}_{3} \mathrm{CN}\left(C_{\mathrm{Hg}(\mathrm{II})}=4.5 \times 10^{-5} \mathrm{M}\right.$, $\left[\mathrm{Cl}^{-}\right]=5 \times 10^{-3} \mathrm{M}, \lambda_{\text {ir }}=254 \mathrm{~nm}$ ).

photoreaction, which is, similarly to the cases without EtOH, accompanied by $\mathrm{Hg}_{2} \mathrm{Cl}_{2}$ production.

Flash Photolysis. A solution of $\mathrm{HgCl}_{4}{ }^{2-}\left(10^{-3} \mathrm{M}\right)$ was also irradiated by $15-\mathrm{ns}$ laser pulses at $266 \mathrm{~nm}$. A long-lived intermediate was detected, the absorption spectrum of which 


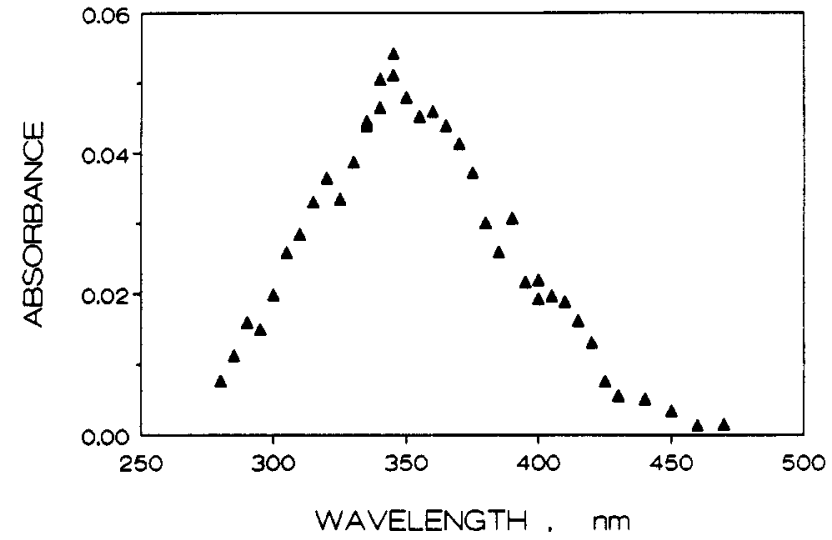

Figure 7. Transient absorption spectrum recorded $5 \mu \mathrm{s}$ after a 266-nm laser pulse in acetonitrile solution of $\mathrm{HgCl}_{4}{ }^{2-}\left(C_{\mathrm{Hg}(\mathrm{II})}=10^{-3} \mathrm{M},[\mathrm{Cl}-]\right.$ $\left.=5 \times 10^{-3} \mathrm{M} . l=1 \mathrm{~cm}\right)$.

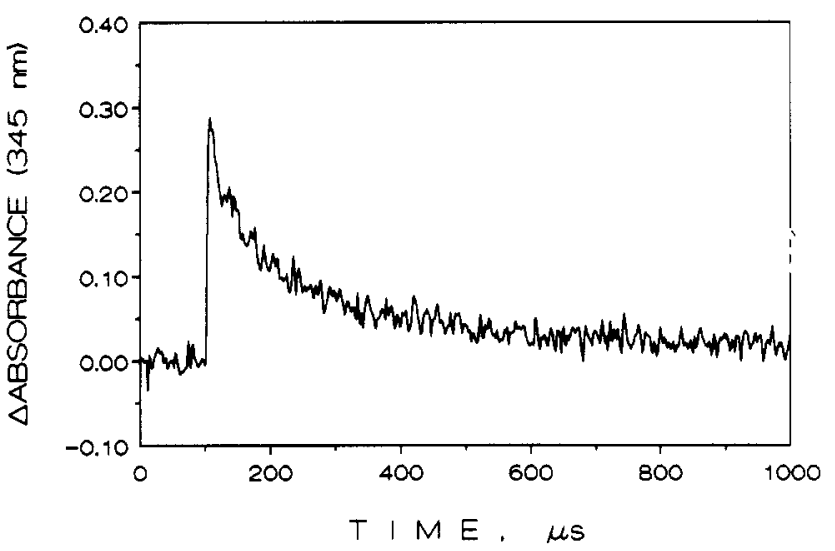

Figure 8. Transient absorption at $345 \mathrm{~nm}$. (Conditions are as in Figure 7.)

displays an intense band at $345 \mathrm{~nm}$ (Figure 7). This fairly well agrees with the spectrum of the $\mathrm{Cl}_{2}^{-}$radical ion in both acetonitrile ${ }^{21}$ and aqueous solutions. ${ }^{22}$ The decay of this species obeys a first-order kinetics with a lifetime of $200 \pm 20 \mu$ s (Figure 8 ). This value of $\tau$ was obtained under both deaerated and airsaturated conditions. Addition of $\mathrm{EtOH}$ (in the same concentration range as applied for continuous irradiations) hardly affects the decay of this intermediate.

\section{Discussion}

Spectroscopy and Equilibria. Although the UV absorption spectrum of $\mathrm{HgCl}_{2}$ in $\mathrm{CH}_{3} \mathrm{CN}$ is significantly different from those of the tri- and tetrachloro species in the respect of both the energy and the intensity of the main band, in all the three cases the most intense electronic transitions are of LMCT type. The deviating molecular structures, bond strengths, orbital symmetries, and energies can cause essential changes in the spectral properties. In the linear $\mathrm{HgCl}_{2}$ complex the only allowed transition is ${ }^{1} \Sigma_{\mathrm{g}}{ }^{+}$ $\rightarrow 1 \prod_{u}$, in which one electron is promoted from the $\pi_{\mathrm{u}} \mathrm{MO}$ mainly composed of the halogen's $\mathrm{p}_{\boldsymbol{\pi}}$ orbital to the $\sigma_{\mathrm{g}}{ }^{+} \mathrm{MO}$, the main component of which is the $\mathrm{Hg}$ 's 6 s orbital. ${ }^{23}$ The $\mathrm{HgCl}_{3}$ - ion is trigonal planar, and its allowed lowest energy transition is ${A_{1}}^{\prime} \rightarrow$ $E^{\prime}$, in which an electron is excited from the $e^{\prime}$ MO consisting mainly of the halogen's nonbonding $p$ orbital to the $a_{1}{ }^{\prime} \mathrm{MO}$ composed of the $6 s$ orbital of mercury. ${ }^{24}$ Finally, $\mathrm{HgCl}_{4}{ }^{2-}$ has a tetrahedral symmetry, and its intense band is considered as an

(21) Bergamini, P.; Maldotti, A.; Sostero, S.; Traverso, O.; Sykora, J. Inorg Chim. Acta 1984, 85, L15.

(22) (a) Grossweiner, L. I.; Matheson, M. S. J. Phys. Chem. 1957, 61, 1089. (b) Edgecombe, F. H. C.; Norrish, R. G. W. Proc. R. Soc. 1959, A253, 154. (c) Anbar, M.; Thomas, J. K. J. Phys. Chem. 1964, 68, 3829.

(23) Koutek, M. E.; Mason, W. R. Inorg. Chem. 1980, 19, 648.

(24) Vogler, A.; Horváth, O. Unpublished results.
${ }^{1} A_{1}-{ }^{1} T_{2}$ transition from the $t_{2}$ MO mainly composed of the chloride's $p_{\pi}$ orbital to the $a_{1}$ MO composed basically of the Hg's $6 \mathrm{~s}$ orbital. ${ }^{12,25}$ In all cases the filled d orbitals are of nonbonding type, and from the $\mathrm{Hg}$ atom essentially the $6 \mathrm{~s}$ and $6 \mathrm{p}$ orbitals contribute to the $\mathrm{Hg}-\mathrm{Cl}$ bond.

According to the data in the literature, the stability constant of $\mathrm{HgCl}_{2}$ in acetonitrile is ca. $10^{35} \mathrm{M}^{-1}$, ${ }^{13}$ while in aqueous systems it is about $10^{13} \mathrm{M}^{-1}$. $^{2}$ This means that dichloromercurate(II) (C $\left.>10^{-5} \mathrm{M}\right)$ does not dissociate to an appreciable extent $(<1 \%)$ even in protic solvents. In the case of $\mathrm{HgCl}_{3}{ }^{-}$, however, the stepwise formation constant, $K_{3}$, in a protic solvent like $\mathrm{MeOH}$ falls below $10^{2} \mathrm{M}^{-1}$. Hence, a considerable excess of ligand is necessary for quantitative formation of trichloromercurate(II). On the contrary, in $\mathrm{CH}_{3} \mathrm{CN}$, which is very weakly coordinated to $\mathrm{Hg}^{2+}$, the relatively high value of $K_{3}\left(10^{6} \mathrm{M}^{-1}\right)^{13}$ results in that chloride ions added to $\mathrm{HgCl}_{2}$ (up to $50 \%$ ) will be entirely taken up by the dichloro complexes. This significant difference between the equilibrium constants in acetonitrile compared to protic solvents remains in the case of $\mathrm{HgCl}_{4}{ }^{2-}$ too. It is demonstrated by the values of $1.07 \times 10^{4} \mathrm{M}^{-1}$ for $K_{4}$ in $\mathrm{CH}_{3} \mathrm{CN}$ against e.g. 5.7 $\mathrm{M}^{-1}$ determined in $\mathrm{MeOH} .{ }^{4}$ Similar tendencies are effective for other halomercurates(II).

Photochemistry. The results of the continuous and flash photolyses unambiguously proved that the primary photoreaction of chloromercurate(II) complexes in $\mathrm{CH}_{3} \mathrm{CN}$ like in water ${ }^{10}$ is an $\mathrm{LMCT}$ process, producing $\mathrm{Hg}(\mathrm{I})$ species and $\mathrm{Cl}$,

$$
\mathrm{HgCl}_{n}^{(n-2)-\stackrel{h \nu}{\rightarrow}} \mathrm{HgCl}_{n-1}^{(n-2)-}+\mathrm{Cl}^{\cdot}
$$

These primary products can undergo a thermal back-reaction (eq 3 ) or react further in different ways (eqs 4-9), where D

$$
\begin{gathered}
\mathrm{HgCl}_{n-1}{ }^{(n-2)-}+\mathrm{Cl}^{\circ} \rightarrow \mathrm{HgCl}_{n}{ }^{(n-2)-} \\
\mathrm{Cl}+\mathrm{Cl}^{-} \rightarrow \mathrm{Cl}_{2}^{-} \\
2 \mathrm{Cl}_{2}^{-} \rightarrow \mathrm{Cl}_{2}+2 \mathrm{Cl}^{-} \\
\mathrm{Cl}_{2}^{-}+\mathrm{Hg}(\mathrm{I}) \rightarrow \mathrm{Hg}(\mathrm{II})+2 \mathrm{Cl}^{-} \\
\mathrm{Cl}^{-} \text {or } \mathrm{Cl}_{2}^{-}+\mathrm{D} \rightarrow 2 \mathrm{Cl}^{-}+\mathrm{P} \\
2 \mathrm{HgCl}_{n-1}{ }^{(n-2)-} \rightarrow \mathrm{Hg}_{2} \mathrm{Cl}_{2}+(2 n-4) \mathrm{Cl}^{-} \quad(n<4) \\
2 \mathrm{HgCl}_{3}{ }^{2-} \rightarrow \mathrm{Hg}^{0}+\mathrm{HgCl}_{4}{ }^{2-}+2 \mathrm{Cl}^{-}
\end{gathered}
$$

represents a reducing agent, which can be the solvent itself or some organic solute added, and $P$ designates the product formed via oxidation of $D$. Disproportionation of $\mathrm{Hg}(\mathrm{I}$ ) species (eq 9) plays an important role only in ligand excess, i.e. in the case of tetrachloromercurate(II).

The lifetime of $\mathrm{Cl}_{2}{ }^{-}$in a deaerated solution of $10^{-3} \mathrm{M} \mathrm{HgCl}_{4}{ }^{2-}$ ( $\tau=200 \mu \mathrm{s}$ ) is close to that measured with hexachlorocyclopentadiene in $\mathrm{CH}_{3} \mathrm{CN}$ exposed to flash photolysis. ${ }^{21}$ Since in the latter case $\mathrm{Cl}_{2}$ - disappears mostly in reactions 5 and 7 , the backreaction between $\mathrm{Cl}_{2}^{-}$and $\mathrm{Hg}(\mathrm{I}$ ) (eq 6) cannot play an important role in this system. A further support to this conclusion is that oxygen does not affect the decay of $\mathrm{Cl}_{2}^{-}$, although it very rapidly reacts with $\mathrm{Hg}(\mathrm{I}){ }^{17,26}$ In the presence of air the overall quantum yield is diminished not only by reaction 3 but via reoxidation of $\mathrm{Hg}(\mathrm{I})$ by $\mathrm{O}_{2}$ too (eq 10 ). One end product of the latter reaction

(25) Sakaki, S.; Hagiwara, N.; Iwasaki, N.; Ohyoshi, A. Bull. Chem. Soc. Jpn. 1977, 50, 14.

(26) Pikaev, A. K.; Sibirskaya, G. K.; Spitsyn, V. I. Dokl. Akad. Nauk SSSR 1975, 224, 638 . 


$$
\mathrm{HgCl}_{n-1}{ }^{(n-2)-}+\mathrm{O}_{2} \rightarrow \mathrm{HgCl}_{n-1}{ }^{(n-3)-}+\mathrm{O}_{2}^{-}
$$

is peroxide, as it was qualitatively detected in air-saturated solutions irradiated. Besides, $\mathrm{O}_{2}$ can react with atomic mercury formed via disproportionation, giving $\mathrm{Hg}_{2} \mathrm{Cl}_{2}$ as an end product.

Addition of ethanol to a deaerated solution of $\mathrm{HgCl}_{4}{ }^{2-}$ significantly enhanced the quantum yield, indicating that EtOH efficiently reacts with one or both of the primary products. Since it does not affect the formation and decay of $\mathrm{Cl}_{2}^{-}$, the mercury(I) species, $\mathrm{HgCl}_{n-1}{ }^{(n-2)-}$, is the more probable candidate for this reaction. This is confirmed by our recent results with the photolyses of $\mathrm{Hg}_{2}{ }^{2+}$ in water-ethanol mixtures. ${ }^{20}$ The suggested primary photoreaction in that system is the cleavage of the $\mathrm{Hg}$ $\mathrm{Hg}$ bond, producing very reactive $\mathrm{Hg}^{+}$species, which can undergo both reduction and oxidation, depending on the oxygen and alcohol content of the solutions. The $\mathrm{HgCl}_{3}{ }^{2-}$ ion must be similarly reactive; hence, in the absence of $\mathrm{O}_{2}$, its reduction by $\mathrm{EtOH}$ gives atomic mercury (eq 11). In aerated solutions, however, no EtOH

$$
\begin{aligned}
& \mathrm{HgCl}_{3}{ }^{2-}+\mathrm{CH}_{3} \mathrm{CH}_{2} \mathrm{OH} \rightarrow \\
& \mathrm{Hg}^{0}+3 \mathrm{Cl}^{-}+\mathrm{CH}_{3} \mathrm{CHOH}+\mathrm{H}^{+}
\end{aligned}
$$

effect was observed, indicating that at these concentrations of $\mathrm{O}_{2}$ (ca. $2 \times 10^{-4} \mathrm{M}$ ) and ethanol $(<0.15 \mathrm{M}$ ) reaction 11 is not competitive enough with the oxidation of $\mathrm{HgCl}_{3}{ }^{2-}$ (eq 10$)$ and the atomic mercury formed can also be rapidly reoxidized.

The quantum yields determined for the different $\mathrm{HgCl}_{n}(n-2)-$ complexes (Table II) involve the effect of ligand number on both the primary photoreaction and those with $\mathrm{HgCl}_{n-1}{ }^{(n-2)-}$. The efficiency of the overall photoinduced reaction is considerably diminished as the number of the coordinated ligands increases. This tendency is effective in both aerated and argon-saturated systems. The lifetime of any excited state is inversely proportional to the oscillator strength, $f{ }^{19 b}$ and in our case the molar absorbance, and thus, $f$ increases upon coordination of more ligands, resulting in a shorter excited-state lifetime and, hence, lower probability for a LMCT reaction. This conclusion is also in accordance with the photoredox behavior of chlorocuprate(II) complexes in acetonitrile. 15,16,27 Besides, the recombination of $\mathrm{HgCl}_{n-1}{ }^{(n-2)-}$ to $\mathrm{Hg}_{2} \mathrm{Cl}_{2}$ may also be hindered by a higher number of ligands (see eq 8 ), and thus the reoxidation of the $\mathrm{Hg}(\mathrm{I})$ monomer (via reactions 3 and 10) can be more efficient.

Acknowledgment. This work was supported by the BMFT and the Fonds der Chemischen Industrie. O.H. is especially grateful to the Alexander von Humboldt Foundation for the fellowship making his research possible at Regensburg University. We thank Dr. Horst Kunkely for the competent technical assistance.

(27) Sykora, J.; Sima, J.; Valigura, D. Chem. Zvesti 1981, 35, 345. 